\title{
Bilirubin Crystal Measurement
}

National Cancer Institute

\section{Source}

National Cancer Institute. Bilirubin Crystal Measurement. NCI Thesaurus. Code C74668.

The determination of the amount of bilirubin crystals present in a sample. 